\title{
Revised Cancer Risk Assessment of Inorganic Arsenic upon Consumption of Tilapia (Oreochomis mossambicus) from Blackfoot Disease Hyperendemic Areas
}

\author{
C.-W. Liu, ${ }^{1}$ F.-M. Huang, ${ }^{1}$ Y.-M. Hsueh ${ }^{2}$ \\ ${ }^{1}$ Ecotoxicological Modeling Center, Department of Bioenvironmental Systems \\ Engineering, National Taiwan University, Taipei, Taiwan, 106, Republic of China \\ 2 Department of Public Health, School of Medicine, Taipei Medical University, Taipei, \\ Taiwan, 110, Republic of China
}

Received: 25 September 2004/Accepted: 9 March 2005

Blackfoot disease is an endemic peripheral vascular disease found in a limited coastal area in the southwest of Taiwan, where water in deep wells contains a high concentration of arsenic. The inhabitants have not drunk well water since many epidemiological studies showed that the exposure to arsenic was strongly associated with disease and cancer. However, groundwater is still utilized in aquaculture (Huang et al. 2003). Arsenic, As, is present in various chemical forms, which can be easily absorbed by aquatic organisms. Arsenic can also accumulate in animal and human food chains. Most dietary arsenic is consumed in fish, shellfish and seafood products. The US Food and Drug Administration (US FDA 1993), in examining the food category, indicated that the fish and other seafood account for $90 \%$ of the total arsenic exposure. Fish are valuable indicators of the bioaccumulation of toxic substances in aquatic organisms. Several arsenic species are present in marine organisms; they include arsenobetaine, arsenocholine, monomethylarsonic acid (MMA), dimethylarsinic acid (DMA), As (V) and As (III). Suhendrayatna et al. (2002) found that freshwater organisms and tilapia mossambica accumulated and transformed arsenic in their bodies. Approximately $90 \%$ of accumulated arsenic was depurated to water. Arsenical toxicity, defined by the prevalence of carcinogenesis and vascular disorders in the former arsenic endemic of southwest coast of Taiwan, follows the order MMA (III) $>$ As (II) $>$ As (V) $>$ MMA (V) $=$ DMA(V) (Lin et al. 1998).

Inorganic arsenic species are more toxic than methyl arsenic species. The US EPA uses inorganic arsenic uptake by various seafood to determine the potential risk to human health. In recent years, several studies focused on assessing the risk of cancer associated with consuming aquatic products in the southwest coastal 
region of Taiwan (Han et al. 1998; Liao and Ling 2003). However, without measuring the inorganic As concentrations they simply assumed that inorganic As constituted $5-10 \%$ of total As in seafood. Using an assumed fraction of inorganic As to assess the health of seafood intake may lead to an erroneous result. This study thus directly measured the concentration of inorganic arsenic species to evaluate the risk to human health in the blackfoot disease area of Taiwan of consuming tilapia. The results are compared with those in other studies to validate the risk assessments in other investigations that made assumptions based on total As concentration.

\section{MATERIALS AND METHODS}

Seventy-one tilapia samples were collected from 11 aquaculture ponds in the Yichu, Hsuehchia, Putai and Peimen from December 2001 to April 2002. Fish samples were frozen while transported from the field to laboratory. Homogenized samples were freeze-dried for $36 \mathrm{~h}$. Homogenized freeze-dried samples of $0.5 \mathrm{~g}$ and $65 \%$ nitric acid of $25 \mathrm{ml}$ were added to a flask. They were boiled and decanted to allow gases to pass through a condenser and digested for $12 \mathrm{~h}$ until the solution was clear. Total arsenic was analyzed by an electro-thermal atomic absorption spectrometer, AAS (AA100 Perkin-Elmer Shelton, USA), and hydride generation, HG (FIAS 400 Perkin-Elmer Shelton, USA) system. Using HG/AAS, $0.5 \%$ $\mathrm{NaBH} 4$ in $0.25 \% \mathrm{NaOH}$ and $1 \mathrm{~N} \mathrm{HCl}$ were added to a digested sample of $200 \mu 1$ to reduce the arsenic to arsine. Then, the total arsenic concentrations were determined. 1.0 1.5 $\mathrm{g}$ of freeze-dried fish dorsal muscle and $150 \mathrm{ml}$ of methanol/water solution $(1 / 1, v / v)$ were placed into a Soxhlet extraction apparatus modified from Gomez-Ariza et al. (2000) and extracted for $16 \mathrm{~h}$. A methanol remove extraction tube was designed to remove the methanol when the extraction was finished. After the methanol was removed, the extract was freeze-dried to a powder and re-dissolved in $10 \mathrm{ml}$ of de-ionized water. The re-dissolved liquids were purified by filtering through $\mathrm{C}_{18}$ cartridges. $A$ high-performance liquid chromatograph, HPLC (Hitachi 7110, Naka, Japan), equipped with an anion column (Machey-Nagel, Nucleosil, $10 \mu \mathrm{m}, 250 \times 4.6 \mathrm{~mm}$ ) and connected to HG/AAS, was used to separate As (III), As (V), MMA and DMA (Fig.1). The analytical procedures for As(III), As(V), MMA and DMA followed closely from our precious study (Huang et al. 2003). The accuracy of procedure was validated by the analysis of standard reference material (SRM) 


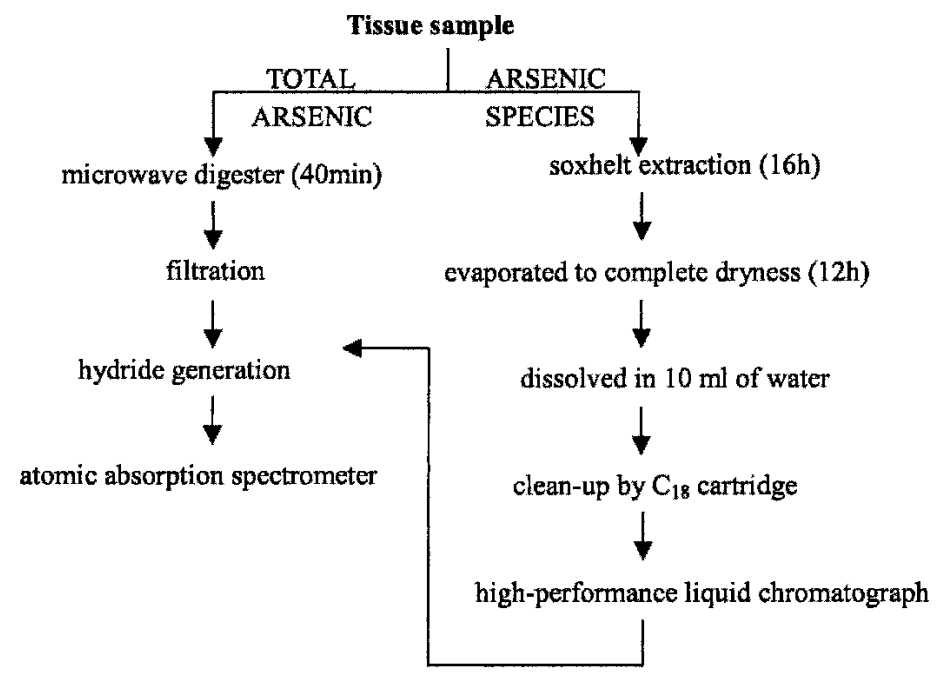

Figure 1. Analytical method for total arsenic and arsenic species.

BCR 627 tuna tissue. Samples were spiked with arsenic species to calculate the recovery rate in every extraction step and laboratory procedure. The coefficient of variation $(\mathrm{CV})$ was used to test the reliability and was less than $5 \%$ for all experiments.

The method for estimating the target cancer risk (TR) is given in the US EPA Region III Risk-Based Concentration Table (US EPA 1996). The risk associated with the carcinogenic effects of inorganic arsenic is expressed as the excess probability of contracting cancer over a lifetime of 70 years. The model for estimating the target cancer risk (lifetime cancer risk) is as follows.

$T R=\frac{E F r \times E D \text { tot } \times S F I \times M C S_{\text {inorg }} \times C P S o}{B W a \times A T c} \times 10^{-3}$

where $T R$ represents the target cancer risk or the risk of cancer over a lifetime; $E F r$ is the exposure frequency (350 days/years); EDtot is the exposure duration (30 years); $S F I$ is the mass of fish ingested (g/day); $M C S_{\text {inorg }}$ is the concentration of inorganic arsenic species in the edible portion of fish $(\mu \mathrm{g} / \mathrm{g})$ wet wt which is determined from measured data and a Monte Carlo simulation; CPSo is the oral carcinogenic potency slope of inorganic arsenic (risk per $\mathrm{mg} / \mathrm{kg} /$ day) $(1.5$ $\mathrm{mg} / \mathrm{kg} /$ day); $B W a$ is the body weight of an adult $(65 \mathrm{~kg})$, and $A T c$ is the averaging 
time for carcinogens (25,550 days). The water contents of an average of $79 \%$ in tilapia were measured and used to convert the dry weight to wet weight of inorganic As concentration in edible portion of tilapia. The above analytical data were used to assess the risk to human health by the consumption of tilapia in the hyperendemic blackfoot disease area.

Based on the measurements of the concentrations of inorganic arsenic species in tilapia, @Risk (Version4.5, Professional Edition, Palisade Crop; USA) software was used to analyze measurements of the concentrations of inorganic arsenic species in tilapia and estimate distribution parameters for inorganic arsenic species. A chi-square test was performed to determine the probability distributions that best-fit $M C S_{\text {inorg. }}$. Moreover, the Monte Carlo method was used to generate the distribution of inorganic arsenic in tilapia from the determined best-fit distributions of concentrations of inorganic arsenic. The $95^{\text {th }}$ percentile $T R$ values were compared with the acceptable human health target cancer risk of $10^{-6}$.

\section{RESULTS AND DISCUSSION}

Table 1 summaries the measured concentrations of arsenic species in tilapia in Yichu, Hsuehchia, Putai and Peimen. The total arsenic concentrations of tilapia among four townships range from $0.512 \mu \mathrm{g} / \mathrm{g}$ to $1.682 \mu \mathrm{g} / \mathrm{g}$ with an average of $0.847 \mu \mathrm{g} / \mathrm{g}$. Han et al. (1998) measured the As concentration of tilapia purchased from Taipei fish market and found that concentrations of total arsenic were $0.13-1.45 \mu \mathrm{g} / \mathrm{g}$ dry wt in tilapia, with a geometric mean concentration of $0.36 \mu \mathrm{g}$ /g dry wt. Their results are lower than our measured As concentration in tilapia indicating the existence of an As contamination of tilapia in the black foot disease areas. The concentrations of As (III) and As (V) range from 0.017 to 0.047 and 0.015 to 0.048 ( $\mu \mathrm{g} / \mathrm{g}$ dry $\mathrm{wt}$ ), respectively. The inorganic arsenic concentrations of tilapia, summation of the concentrations of As (III) and As (V), range from $0.032 \mu$ $\mathrm{g} / \mathrm{g}$ to $0.095 \mu \mathrm{g} / \mathrm{g}$ with a geometric mean of $0.053 \mu \mathrm{g} / \mathrm{g}$. Generally, inorganic arsenic is more toxic and harmful than organic arsenic (Edmonds and Francesconi 1993).

Friberg (1988) noted that inorganic arsenic in marine organisms constitutes $2-10 \%$ of the total arsenic in such organisms. In this study, inorganic arsenic is found to constitute $5.6-12.8 \%$ with a geometric mean of $6.3 \%$. 
Table 1. Measured concentrations of arsenic species (meantstandard error; $\mu \mathrm{g} / \mathrm{g}$ ) in tilapia in the Putai, Yichu, Hsuehchia and Peimen.

\begin{tabular}{cccccc}
\hline $\begin{array}{c}\text { Arsenic } \\
\text { Species }\end{array}$ & $\begin{array}{c}\text { Putai } \\
(16)^{\mathrm{a}}\end{array}$ & $\begin{array}{c}\text { Yichu } \\
(21)\end{array}$ & $\begin{array}{c}\text { Hsuehchia } \\
(28)\end{array}$ & $\begin{array}{c}\text { Peimen } \\
(6)\end{array}$ & $\begin{array}{c}\text { Average } \\
(71)\end{array}$ \\
\hline $\mathrm{As}(\mathrm{III})$ & $0.047 \pm 0.076$ & $0.017 \pm 0.014$ & $0.019 \pm 0.017$ & $0.039 \pm 0.064$ & $0.026 \pm 0.043$ \\
$\mathrm{As}(\mathrm{V})$ & $0.048 \pm 0.073$ & $0.015 \pm 0.013$ & $0.024 \pm 0.030$ & $0.028 \pm 0.018$ & $0.027 \pm 0.041$ \\
$\mathrm{MMA}$ & $0.023 \pm 0.046$ & $0.007 \pm 0.013$ & $0.007 \pm 0.023$ & $0.001 \pm 0.002$ & $0.010 \pm 0.027$ \\
DMA & $0.358 \pm 0.429$ & $0.122 \pm 0.104$ & $0.113 \pm 0.110$ & $0.060 \pm 0.016$ & $0.175 \pm 0.240$ \\
Inorganic As & $0.095 \pm 0.149$ & $0.032 \pm 0.027$ & $0.043 \pm 0.047$ & $0.067 \pm 0.082$ & $0.053 \pm 0.084$ \\
Total As & $1.682 \pm 1.352$ & $0.512 \pm 0.253$ & $0.690 \pm 0.350$ & $0.522 \pm 0.402$ & $0.847 \pm 0.825$ \\
Inorganic As/ & 5.6 & 6.3 & 6.2 & 12.8 & 6.3 \\
Total As (\%) & & & & & \\
\hline
\end{tabular}

()$^{\mathrm{a}}$ : the number in the parenthesis denotes the sample number.

Fig. 2 plots the determined goodness-of-fit of the lognormal probability distribution function of inorganic arsenic concentrations ( $\mu \mathrm{g} / \mathrm{g}$ dry wt), based on the measured As concentration in tilapia in the blackfoot disease area of Taiwan, using Monte Carlo simulation. The probability distributions of inorganic As concentrations were used to assess the risk to human health. The mass, 10-70 g/day, of fish ingested by adults in Taipei, Taiwan, according to Han et al. (1998), was used to evaluate the risk to human health. The box-and-whisker plot (Fig. 3) shows that the $95^{\text {th }}$ percentile potential risks of cancer from total inorganic arsenic, range from $3.54 \times 10^{-6}$ to $2.48 \times 10^{-5}$, given the consumption of tilapia harvested in the blackfoot disease area of Taiwan. The human health cancer risk $95^{\text {th }}$ percentile TR value estimated using total inorganic arsenic exceeds $10^{-6}$, indicating the existence of a potential health cancer risk. Han et al. (1998) assumed that inorganic arsenic constituted $10 \%$ of all arsenic in seafood of $0.036 \mu \mathrm{g} / \mathrm{g}$ which was lower than our measured inorganic As concentration of $0.053 \mu \mathrm{g} / \mathrm{g}$. However, they failed to convert the dry wt As concentration to wet wt. The assessed risks by Han et al. (1998) using the dry wt As concentration to the population of cancer from consuming $10-70 \mathrm{~g} / \mathrm{d}$ of tilapia ranges from $8.74 \times 10^{-6}$ to $6.56 \times 10^{-5}$ which are higher than our estimated. Liao and Lin (2003) assumed that inorganic arsenic constituted $5 \%$ of arsenic in tilapia. The highest $95^{\text {th }}$ percentile of potential health risk from inorganic As ranged from $1.92 \times 10^{-4}-5.25 \times 10^{-4}$ for Taipei city residents who ate 10-70 g/day of tilapia harvested from Hsuehchia fish farms, but was 7.36 $\times 10^{-4}-1.12 \times 10^{-3}$ for subsistence fishermen who ate $48-143 \mathrm{~g} /$ day. The unrealistic, 


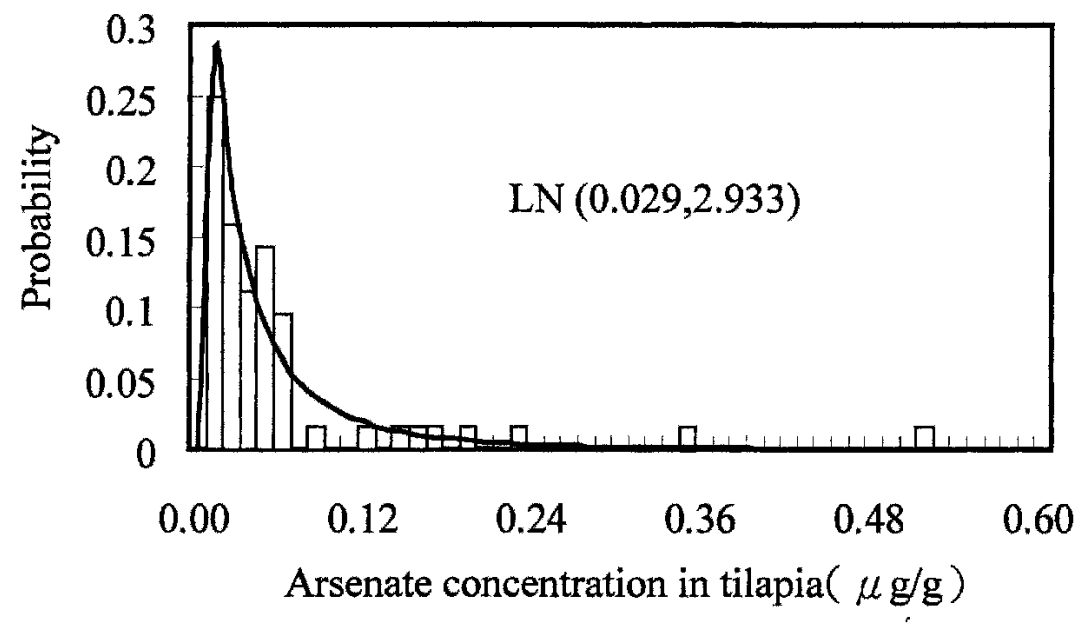

Figure 2. Monte Carlo-simulated lognormal probability distribution function, LN (geometric mean, geometric standard deviation), of inorganic arsenic concentrations in tilapia based on data measured in blackfoot disease area in Taiwan.

high risks estimated by Liao and Ling (2003) are resulting from the use of bioaccumulation factor to estimate As concentration in tilapia and the fail to convert the dry wt As concentration to wet wt. In the risk assessment, the assumptions adopted should be clearly stated and validated carefully to prevent confusion and unnecessary adverse impact on society (Guo 2002). The parameters adopted in the risk assessment are the consumption rates, human exposure, likely exposed numbers and type, and the possible exposure pathways; all these parameters have some degree of uncertainty. For instance, the consumption rates spatially vary. Han et al. (1998) assumed consumption rates of 10-70 g/day by adults in Taipei city, Taiwan, but Liao and Ling (2003) reported consumption rates of 48-143 $\mathrm{g} /$ day for subsistence fishermen in the blackfoot disease area. Additionally, the risk model proposed by the US EPA is based on a study of skin cancer, which is not fatal in most cases (Brown et al. 1997a). Brown et al. (1997b) considered the uncertainty of the risk model at low doses of inorganic arsenic. A meta-analysis also indicates that this model may overestimate risks at exposure levels of under $0.27 \mathrm{ppm}$ (Guo and Valberg 1997). The fact that the body may detoxify As by methylation suggests that dose-response curve of arsenic is not linear at low doses. Thus, the cancer slope factor based on the linear model may over-estimate cancer risks at low doses (US EPA 1988). Other factors, including 


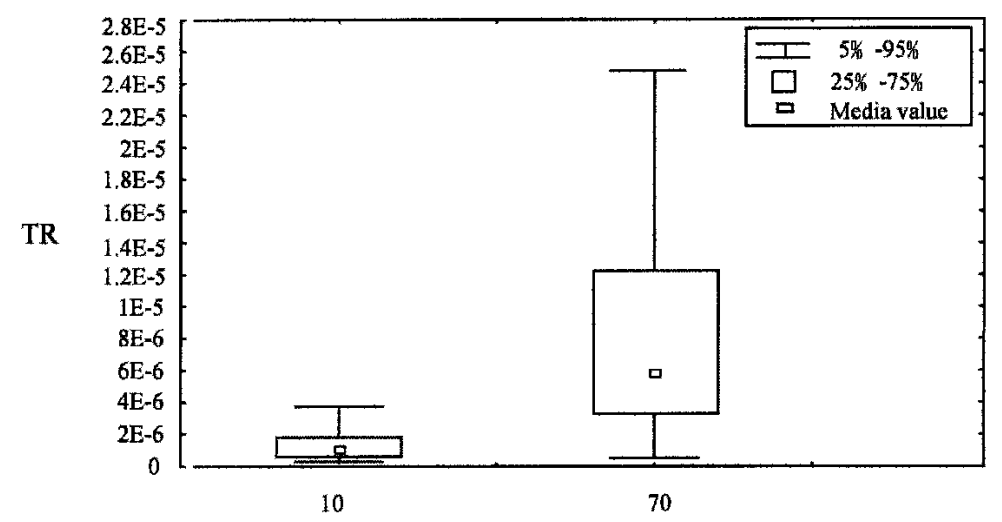

Fish consumption rate (g/d)

Figure 3. Box-and-whisker plot of the estimated target cancer risk for inorganic arsenic due to the consumption of $10-70 \mathrm{~g} /$ day of tilapia harvested from the blackfoot disease area.

the complex processes of inorganic arsenic methylation, and the mechanisms by which arsenic- induces stress in proteins require further investigation Additionally, there are a lot of factors that modify the body burden of arsenic after the consumption of tilapia. Therefore, the measurement of arsenic in body fluid is critical to the determination of cancer risk from such consumption. Since the study did not conduct the body burden analysis, the potential shortcoming in the estimated cancer risk to human health needs to be noticed.

Acknowledgment. We thank the National Science Council of the Republic of China for financially supporting this research under Contract No. NSC 91-2313-B-002-270.

\section{REFERENCES}

Brown KG, Guo HR, Kuo TL, Greene HL (1997a) Skin cancer risk and inorganic arsenic: uncertainty-status of risk. Risk Analysis 17:37-42

Brown KG, Guo HR, Greene HL (1997b) Uncertainty in cancer risk at low doses of inorganic arsenic. Human Ecol Risk Assess 3:351-362

Edmonds JS, Francesconi KA (1993) Arsenic in seafoods: human health aspects 
and regulations. Mar Pollut Bull 26: 665-674

Friberg L (1988) The GESAMP evaluation of potentially harmful substances in fish and other seafood with special reference to carcinogenic substances. Aquat Toxicol 11: 379-393

Gomez-Ariza JL, Sanchez-Rodas D, Giraldez I, Morales E (2000) Comparison of biota ample pretreatments for arsenic speciation with coupled HPLC-HG -ICP-MS. Analyst 125: 401-407

Guo HR, Valberg PA (1997) The validity of US EPA's cancer risk assessment for arsenic at low level exposures: A likelihood ratio approach. Environ Geochem Health 19: 133-141

Guo HR (2002) Cancer risk assessment for arsenic exposure through oyster consumption. Environ Health Perspectives 110: 123-124

Han BC, Jeng WL, Chen RY, Fang GT, Hung TC, Tseng RJ (1998) Estimation of target hazard quotients and potential health risks for metals by consumption of seafood in Taiwan. Arch Environ Contam and Toxicol 35: 711-720

Huang YK, Lin KH, Chen HW, Chang CC, Liu CW, Yang MH, Hsueh YM (2003) Arsenic species contents at aquaculture farm and in farmed mouthbreeder (Oreochromis mossambicus) in blackfoot disease hyperendemic areas. Food Chem Toxicol 41: 1491-1500

Liao CM, Ling MP (2003) Assessment of human health risks for arsenic bioaccumulation in tilapia (Oreochromis mossambicus) and large-scale mullet (Liza macrolepis) from blackfoot disease area in Taiwan. Arch Environ Contam Toxico 145: 264-272

Lin TH, Huang YL, Wang MY (1998) Arsenic species in drinking water, hair, fingernails, and urine of patients with blackfood disease. J Toxicol Environ Health Part A 53: 85-93

Suhendrayatna, Ohki A, Nakajima T, Maeda S (2002) Studies on the accumulation and transformation of arsenic in freshwater organisms II. Accumulation and transformation of arsenic compounds by tilapia mossambica. Chemosphere 46: 325-331

US FDA (1993) Guidance document for arsenic in shellfish. US Food and Drug Administration, Washington, DC, p 25-27

US EPA (1988) Special report on ingested inorganic arsenic: Skin cancer; nutritional essentiality. EPA/625/3-87/013, U.S. Environmental Protection Agency, Risk Assessment Forum, Washington, DC

US EPA (1996) Risk-based concentration table, Region 3, U.S. Environmental Protection Agency, Philadelphia, PA 